\title{
Sphingosine-1-phosphate receptor subtype 1 activation in the central nervous system contributes to morphine withdrawal in rodents
}

Timothy M. Doyle 1,2, Mark R. Hutchinson 3,4,5, Kathryn Braden 1,2, Kali Janes ${ }^{2}$, Vicky Staikopoulos ${ }^{3,4,5}$, Zhoumou Chen ${ }^{1,2}$, William L. Neumann ${ }^{6}$, Sarah Spiegel ${ }^{7}$ and Daniela Salvemini ${ }^{1,2^{*}}$ (D)

\begin{abstract}
Opioid therapies for chronic pain are undermined by many adverse side effects that reduce their efficacy and lead to dependence, abuse, reduced quality of life, and even death. We have recently reported that sphingosine-1-phosphate (S1P) 1 receptor (S1PR1) antagonists block the development of morphine-induced hyperalgesia and analgesic tolerance. However, the impact of S1PR1 antagonists on other undesirable side effects of opioids, such as opioid-induced dependence, remains unknown. Here, we demonstrate that naloxone-precipitated morphine withdrawal in mice altered de novo sphingolipid metabolism in the dorsal horn of the spinal cord and increased S1P that accompanied the manifestation of several withdrawal behaviors. Blocking de novo sphingolipid metabolism with intrathecal administration of myriocin, an inhibitor of serine palmitoyltransferase, blocked naloxone-precipitated withdrawal. Noteworthy, we found that competitive (NIBR-15) and functional (FTY720) S1PR1 antagonists attenuated withdrawal behaviors in mice. Mechanistically, at the level of the spinal cord, naloxone-precipitated withdrawal was associated with increased glial activity and formation of the potent inflammatory/neuroexcitatory cytokine interleukin-1 $\beta$ (IL-1 13$)$; these events were attenuated by S1PR1 antagonists. These results provide the first molecular insight for the role of the S1P/S1PR1 axis during opioid withdrawal. Our data identify S1PR1 antagonists as potential therapeutics to mitigate opioid-induced dependence and support repurposing the S1PR1 functional antagonist FTY720, which is FDA-approved for multiple sclerosis, as an opioid adjunct.
\end{abstract}

Keywords: Sphingosine-1-phosphate, Sphingosine-1-phosphate receptor subtype 1, Naloxone-precipitated withdrawal, GFAP, CD11b, IL-1ß

\section{Introduction}

Chronic neuropathic pain is difficult to treat and sufferers are often left with opioids as the only option for some pain relief. However, the long-term use of opioids, such as morphine, is limited by the development of paradoxical

\footnotetext{
* Correspondence: daniela.salvemini@health.slu.edu

'Henry and Amelia Nasrallah Center for Neuroscience, Saint Louis University School of Medicine, 1402 South Grand Blvd, St. Louis, MO 63104, USA

${ }^{2}$ Department of Pharmacology and Physiology, Saint Louis University School of Medicine, 1402 South Grand Blvd, St. Louis, MO 63104, USA

Full list of author information is available at the end of the article
}

painful hypersensitivity (opioid-induced hyperalgesia, $\mathrm{OIH}$ ) and tolerance to the antinociceptive effects of opioids over time [1, 2]. OIH coupled with tolerance often prompts extended use and escalated dosages that can trigger further changes, which eventually lead to additional unwanted side effects such as dependence, addiction, and abuse [1,2]. Despite the serious side effects associated with long-term opioid use, this class of drugs remains the gold standard for pain management [3].

Identifying opioid-sparing approaches that also mitigate the development of dependence, addiction, and 
abuse requires continued investigation of the molecular underpinnings of how opioids cause such adverse effects. Emerging evidence shows that long-term morphine exposure can lead to dysregulation of sphingolipid metabolism within the dorsal horn spinal cord [4, 5]. Sphingolipids were once thought to serve mainly as structural cellular components, but now are recognized to be potent signaling molecules [6]. Ceramide and sphingosine-1-phosphate (S1P) are among the beststudied sphingolipids [6] and have been implicated in numerous disease states $[6,7]$, including pain and several of its co-morbidities $[8,9]$. S1P is formed from its precursor ceramide produced by activation of enzymes in the sphingomyelin (sphingomyelinase; SMase), and/or de novo (serine palmitoyl transferase, SPT) metabolic pathways (Fig. 1a) $[6,10]$. Ceramide is hydrolyzed to sphingosine, which is then phosphorylated by sphingosine kinases to produce S1P $[6,10]$. Our recent work uncovered an important link within the central nervous system (CNS) between opioids and sphingolipids in the neurobiology of $\mathrm{OIH}$ and antinociceptive tolerance $[4$, 5]. We found that repeated administration of morphine in rodents altered sphingolipid metabolism in the CNS and increased the levels of ceramide and S1P, which directly contributed to the development of OIH and tolerance [5]. Once formed, S1P is released from cells and initiates autocrine and paracrine signaling by activating any of the five known G protein-coupled S1P receptor subtypes (S1PR1-5) (inside-out signaling) [11]. S1P signaling is terminated by S1P lyase and phosphatases [12]. Except for SIPR4, all S1PRs are found throughout the CNS, but their cell distribution varies [13-16]. We have recently identified that S1PR1 was responsible for transducing the effects of S1P in the development of $\mathrm{OIH}$ and tolerance [4]. Its inhibition with S1PR1 functional and competitive antagonists significantly attenuated the development of OIH and tolerance, identifying S1PR1 as a target for therapeutic intervention for $\mathrm{OIH}$ and tolerance [4].

The impact of S1PR1 antagonists on other undesirable side-effects of opioids remains unknown. Opioid withdrawal is perhaps one of the most damaging side effects, as the unpleasant physical and affective symptoms associated with withdrawal compel patients to continue taking opioids despite the risks [17]. These symptoms emerge in patients within hours after the last dose and some affective symptoms such as anxiety, depression, and cravings can persist for up to several weeks in chronic users [18]. It is important to find treatments that can help manage these symptoms to facilitate the cessation of opioid use and prevent potential relapse. Guided by our previous work, we now present the first evidence that S1PR1 antagonists may also have a use in opioidinduced dependence.

\section{Materials and methods Study approval}

All animal studies were performed in accordance with the International Association for the Study of Pain, the National Institutes of Health guidelines on laboratory animal welfare and approved by the Saint Louis University Institutional Animal Care and Use Committee, and the University of Adelaide Animal Ethics Committee (Ethics approval number M-60-2009).

\section{Animal}

Pathogen-free adult male BALB/c mice (20-30 g starting weight) from Envigo Laboratories (Fredrick, MD, USA) or Laboratory Animal Services (University of Adelaide, Adelaide, AU) were housed 4-5 per cage. All animals were kept in a controlled environment $(12 \mathrm{~h}$ light/dark cycle) with food and water available ad libitum. Animals were randomly separated into treatment groups for each experiment. Experimenters were blinded to treatments during behavior and biochemical assessments.

\section{Test compounds}

Morphine sulfate was obtained as a kind gift from Mallinckrodt Pharmaceuticals (St. Louis MO, USA) or from the NIDA drug repository (Bethesda MD, USA). Fingolimod (FTY720; Gilenya ${ }^{\circ}$ ) was purchased from Cayman Chemical (Ann Arbor, MI, USA). NIBR-15 was synthesized as previously described [19].

\section{Experiments}

\section{Naloxone-precipitated withdrawal}

For all studies, chronic morphine dependence was induced as previously described [20] in male BALB/C mice by repeated intraperitoneal (i.p., $0.2 \mathrm{ml}$ ) injections of morphine given twice daily (morning and afternoon) for three consecutive days with an escalating dose schedule: day 1 ( 7.5 and $15 \mathrm{mg} / \mathrm{kg}$ ), day 2 (30 and $30 \mathrm{mg} / \mathrm{kg}$ ), and a single dose on day $3(30 \mathrm{mg} / \mathrm{kg})$. Saline control groups of age-matched male mice received an equal number of saline injections over 3 days. To induce withdrawal behaviors, naloxone $(10 \mathrm{mg} / \mathrm{kg}$, i.p., $0.2 \mathrm{ml})$ was injected $1 \mathrm{~h}$ after the last morphine injection on day 3 (Fig. 1a). Animals not receiving naloxone were given an i.p. injection of saline $(0.2 \mathrm{ml})$.

\section{Opioid withdrawal behaviors}

Behaviors associated with withdrawal in rodents (jumping, front paw shakes, and hunching) [20-23] were measured as previously described [20]. The animals were placed into individual plexiglass observation cylinders $(25 \mathrm{~cm} \times 11 \mathrm{~cm})$ and the incidence of jumping, front paw shakes, and hunching were recorded for $30 \mathrm{~min}$. 


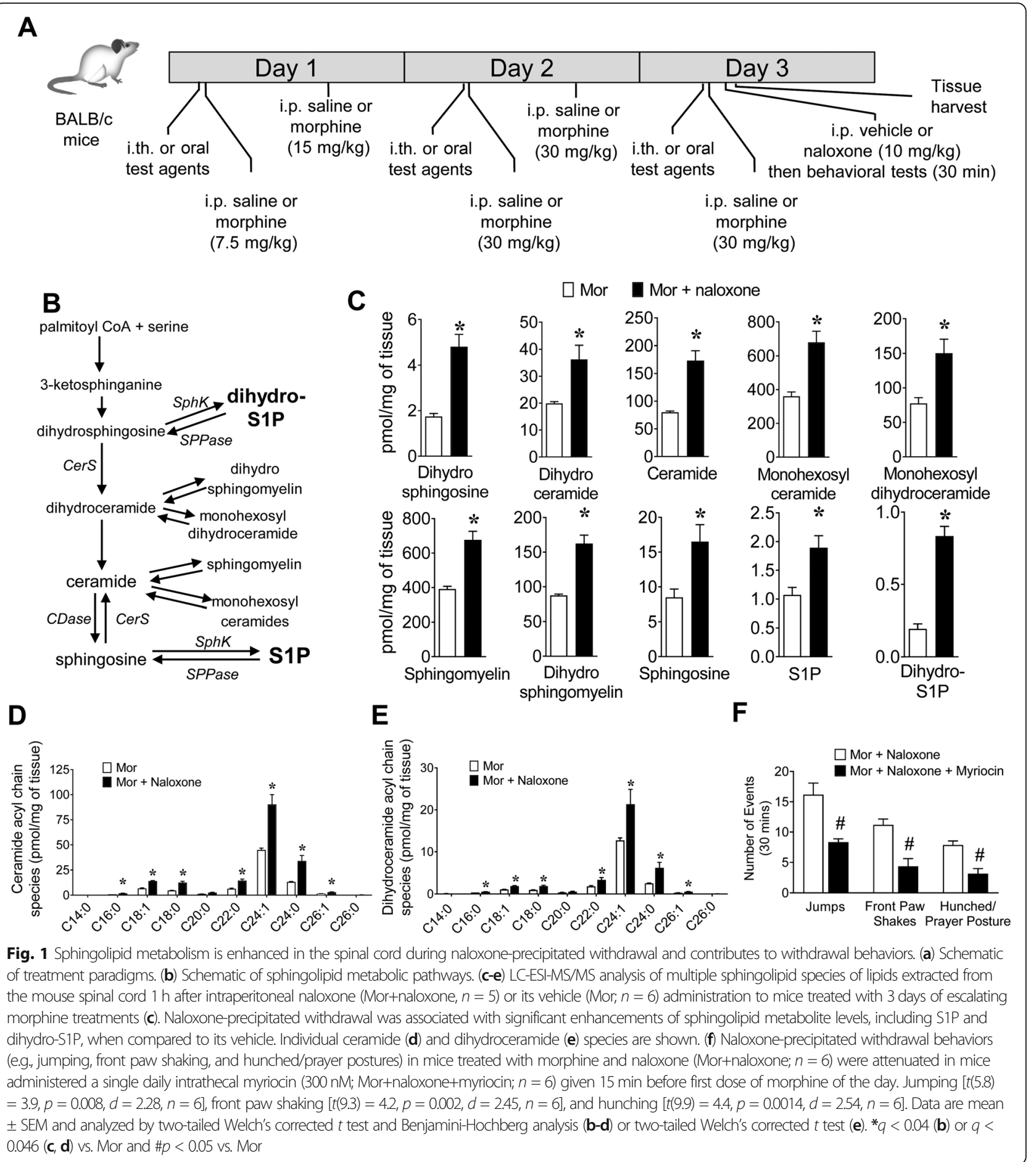

Study 1: Spingolipidomics Male mice were given the escalating doses of morphine and then treated with saline $(n=5)$ or naloxone $(n=6)$ on day 3. Salineperfused lumbar portions of the spinal cords were harvested $30 \mathrm{~min}$ after behavioral testing for sphingolipidomics.
Study 2: Inhibition of morphine withdrawal by myriocin Male mice were given the escalating doses of morphine (i.p.) in the presence of myriocin $(n=6)$ or vehicle (saline, $n=6)$. Myrioicin $(300 \mathrm{nM})$ or its vehicle was given $15 \mathrm{~min}$ before the first morphine injection of morphine each day for 3 days via acute intrathecal (i.th., 
$5 \mu \mathrm{L})$ injection as previously described $[24,25]$. The dose of myriocin was chosen from previous studies [5, 26]. All animals received an i.p. injection of naloxone on day 3.

Study 3: Inhibition of morphine withdrawal by S1PR1 antagonist Male mice were given the escalating doses of morphine (i.p.) in the presence of NIBR-15 (3 $\mathrm{mg} / \mathrm{kg} /$ day; $n=4)$ or vehicle $(2-5 \%$ DMSO in $0.5 \%$ methylcellulose, $n=4$ ) or in the presence of FTY720 $(0.1 \mathrm{mg} / \mathrm{kg} /$ day, $n=12)$ or vehicle $(2-5 \%$ DMSO in $0.5 \%$ methylcellulose, $n=11$ ). Test agents were given by oral gavage $(0.2 \mathrm{ml})$ as previously described [27]. The doses of NIBR-15 and FTY720 were chosen from previous studies [27]. All animals received the i.p. injection of naloxone on day 3 .

Study 4: Neuroinflammation Male mice were given saline $(n=7)$ or the escalating doses of morphine after oral administration of vehicle $(n=6)$ or FTY720 (0.1 $\mathrm{mg} / \mathrm{kg} /$ day, $n=3)$. On day 3 , saline-treated mice received i.p. saline vehicle injection and all morphine treated mice received the i.p. injection of naloxone. Saline-perfused lumbar portions of the spinal cords were harvested $30 \mathrm{~min}$ after behavioral testing for Western blot and ELISA.

\section{Sphingolipid analysis by mass spectrometry}

Sphingolipids were extracted and quantified by liquid chromatography-electrospray ionization-tandem mass spectrometry (LC-ESI-MS/MS) using a 5500 QTRAP (ABI, Ramingham, MA) as previously described [28].

\section{Western blot analyses}

Mouse spinal cords were homogenized in cell lysis buffer containing $1 \%$ protease inhibitor cocktail (Sigma-Aldrich, Sydney, Australia, catalog \# P8340), sonicated, then centrifuged at 14,000 RPM for 5 min and supernatants collected. Lysate proteins $(30 \mu \mathrm{g}$ determined by BCA assays) were separated on $8 \%$ or $10 \%$ sodium dodecyl sulfate-polyacrylamide gels and transferred to nitrocellulose. Membranes were treated overnight at $4{ }^{\circ} \mathrm{C}$ with antibodies to glial fibrillary acid protein (GFAP) (1: 3000, Santa Cruz Biotechnology, Dallas, USA, catalog \# sc-6170) or CD11b (1:2000, Santa Cruz Biotechnology, USA, catalog \# sc-6614) followed by secondary antibodies for $1.5 \mathrm{~h}$. Immunoblots were incubated for $1 \mathrm{~min}$ with the enhanced chemiluminescence detection reagent, and visualized using a LAS 4000 imaging system (GE Healthcare, UK). The absorbance of protein bands of interest were then quantified using the ImageQuant TL software (GE Healthcare, UK). Subsequently, membranes were washed and then immunoblotted with $\beta$ actin antibody $(1: 10,000$, Sigma-Aldrich, Australia, catalog \# A3854) as a marker of total protein loaded per each lane. GFAP and CD11b protein levels were normalized relative to $\beta$-actin levels. Adjustments to blot images for publication were limited to linear brightness and contrast or color inversion using Image J v.1.47 [29] where noted. All blot images were cropped for the clarity of data presentation.

\section{Cytokine ELISA}

The levels of cytokines in spinal cord lysates were assessed using commercially available ELISA kits (R\&D Systems, Minneapolis MN, USA) in accordance with the manufacturer's protocol.

\section{Statistics}

Data are expressed as mean \pm SEM for $N$ animals as noted. Data were excluded only if animals showed signs of illness not related to study manipulation or intervention or if a data point was considered an outlier by twotailed Grubb's test $(p<0.05)$. Sphingolipidomic data were analyzed by two-tailed, Welch's corrected $t$ test and adjusted for the false discovery rate determined by Benjamini-Hochberg method $(Q<0.05)$. All other data were analyzed by two-tailed, Welch's corrected $t$ test or one-way ANOVA with Dunnett's comparisons with significance determined at $P<0.05$. All data were analyzed using GraphPad Prism (version 8.0.1 for Windows, GraphPad Software, San Diego CA USA, www.graphpad. com).

\section{Results and discussion}

Mice were treated with escalating doses of morphine (i.p.) before receiving a single i.p. dose of naloxone or vehicle (Fig. 1a). LC-ESI-MS/MS analysis of multiple sphingolipid species in the dorsal horn of the spinal cord harvested $1 \mathrm{~h}$ after naloxone or vehicle revealed that sphingolipid metabolism was dramatically altered in mice given naloxone after morphine than mice given the vehicle after morphine (Fig. 1). Specifically, intermediates of de novo biosynthesis of sphingolipids, dihydrosphingosine, and dihydroceramide were increased following naloxone, implicating enhanced de novo biosynthesis of sphingolipids in naloxone-precipitated withdrawal (Fig. 1b, c). Ceramides, monohexosylceramides, monohexosyldihydroceramides, sphingomyelins, and dihydrosphingomyelins were also concomitantly increased (Fig. 1c-d). Importantly, the dysregulation of sphingolipid metabolism led to significant increases in the levels of sphingosine and the bioactive sphingolipid metabolites, S1P, and dihydro-S1P (Fig. 1c). These changes accompanied a significant increase in the incidence of several behaviors that have been longassociated with opioid withdrawal in rodent models (e.g., jumping, front paw shaking, and hunched/prayer 
postures) (Fig. 1f). To further investigate the link between de novo sphingolipid biosynthesis and the development of withdrawal behaviors, we co-treated mice with myriocin to inhibit serine palmitoyltransferase, the first and rate-limiting enzyme of this pathway [30]. The incidences of naloxone-precipitated withdrawal behaviors were significantly reduced in mice receiving a daily intrathecal injection of myriocin $15 \mathrm{~min}$ before the first morphine dose of the day than those receiving its vehicle (Fig. 1f). These results suggest that alterations in de novo sphingolipid biosynthesis within the spinal cord are functionally linked to withdrawal behaviors.

Since our sphingolipidomic data revealed that S1P and dihydro-S1P increased in the spinal cord with naloxoneprecipitated withdrawal and our previous studies showed the strong contributions of S1PR1 to OIH and tolerance [4], we used the S1PR1 antagonists NIBR-15 and FTY720 to investigate the role of S1PR1 in withdrawal behaviors. NIBR-15 is a potent and highly selective S1PR1 competitive antagonist [19]; whereas, FTY720 is a S1PR1 functional antagonist [31]. FTY720, when phosphorylated by sphingosine kinase 2 to its active counterpart FTY720-P, acts as an S1P agonist at all S1PRs, except S1PR2, but functionally inhibits S1PR1 signaling after binding to S1PR1 and causing sustained depletion of the receptor at the plasma membrane [31]. Mice were given NIBR-15 or FTY720 15 min before the first dose of morphine or saline of the day (Fig. 1a). Coadministration of NIBR-15 or FTY720 (Fig. 2a, b) with morphine significantly reduced the incidence of naloxone-precipitated withdrawal behaviors, unraveling a role for S1PR1.

S1PR1 is found throughout the CNS including the spinal cord and expressed preferentially in glial cells, in particular in astrocytes $[13,16,32]$. Recent evidence suggests that glia play an important role in opioid use disorders [33, 34]. Both astrocytes and microglia within the dorsal horn spinal cord are activated following prolonged exposure to opioids [35-39]. Glial cells are essential for the development of many opioid-induced adverse effects including withdrawal [22, 40, 41].

Once activated, glial cells release various inflammatory cytokines, including tumor necrosis factor (TNF), interleukin-1 $\beta$ (IL-1 $\beta$ ), and interleukin-8 (IL-8) [22, 4042]. During withdrawal, when opioid receptor activation is either spontaneously precipitated or abruptly ceased,
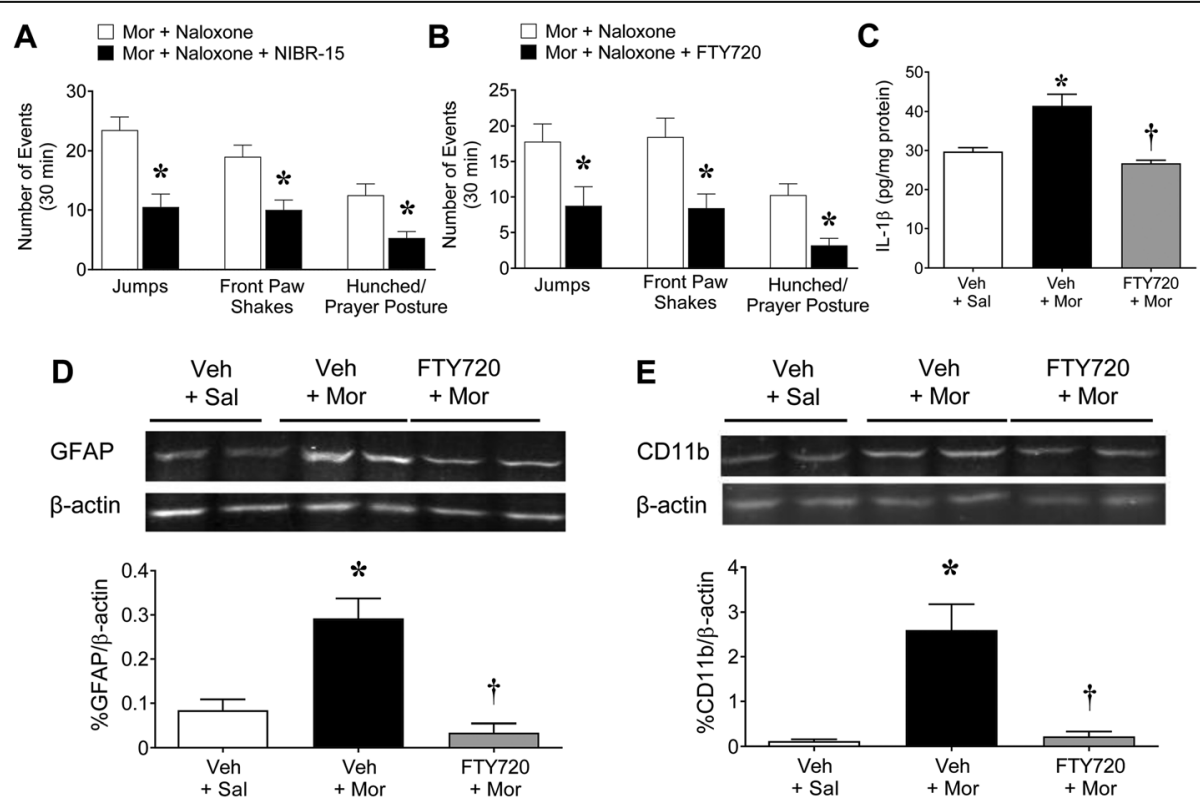

Fig. 2 S1PR1 antagonists attenuate naloxone-precipitated withdrawal and associated neuroinflammation in mice. Naloxone-precipitated withdrawal behaviors in mice treated with morphine and naloxone (Mor+naloxone; $\mathbf{a}: n=4, \mathbf{b}: n=10-11$ ) were attenuated in mice administered oral NIBR-15 (Mor+naloxone +NIBR-15; 3 mg/kg/day; $n=4 ;$ a) or FTY720 (Mor+naloxone+FTY720; 0.1 mg/kg/day; $n=12 ;$ b). Jumping [a: $t(6.0)=4.1, p=0.0060, d_{a d j}$ $\left.=1.2 ; \mathbf{b}: t(20)=2.5, p=0.023, d_{a d j}=0.85\right]$; front paw shaking [a: $\left.t(5.9)=3.5, p=0.014, d_{a d j}=1.0 ; \mathbf{b}: t(19)=3.0, p=0.0070, d_{a d j}=1.0\right] ;$ and hunching [a: $\left.t(4.8)=3.2, p=0.024, d_{a d j}=0.93 ; \mathbf{b}: t(17)=3.8, p=0.0014, d_{a d j}=1.3\right]$. Naloxone-precipitated withdrawal was associated with increased levels of IL-1 $\beta$ $(\mathbf{c} ; n=5)$, GFAP $(\mathbf{d} ; n=6)$, and CD11b $(\mathbf{e} ; n=6)$ in mice spinal cords (Mor+Nal) compared to mice treated with morphine alone $($ Mor; $\mathbf{c}: n=7, \mathbf{d}: n=4$, e: $n=7$ ). Co-administration with FTY720 blocked these events (Mor+Nal + FTY720; $0.1 \mathrm{mg} / \mathrm{kg} / \mathrm{day} ; n=3 ; \mathbf{c}-\mathbf{e}$ ). In $\mathbf{b}$, one animal in the Mor+naloxone group was excluded from the jumping data as a high outlier (Grubb's test). Images have been cropped and adjustments to brightness and contrast were performed across the blots for clarity by Image J [29]. Results are expressed as mean \pm SEM and analyzed by (a-b) two-tailed unpaired Welch's corrected $t$ test. ${ }^{*} P<0.05$ vs. Mor+naloxone or (c-e) two-tailed, one-way ANOVA with Dunnett's comparisons. [Treatment: $(\mathbf{c}) F(2,13)=14, p=0.00063$, $\left.\eta^{2}=0.68 ;(\mathbf{d}) F(2,13)=14, p=0.00060, \eta^{2}=0.68 ;(\mathbf{e}) F(2,10)=9.5, p=0.0049, \eta^{2}=0.65\right] . * p<0.05 \mathrm{vs}$. Mor and $\mathbf{t} p<0.05 \mathrm{vs}$. Mor $+\mathrm{Nal}$ 
this inflammatory environment amplifies neuronal excitability and the withdrawal symptoms [43]. We have recently shown that intrathecal activation of S1PR1 with the highly selective S1PR1 agonist SEW2871 activated the nod-like receptor family, pyrin domain containing 3 (NLRP3) inflammasome and increased IL-1 $\beta$; these effects occurred predominantly through astrocyte-specific S1PR1 [44]. In mice exhibiting naloxone-precipitated withdrawal behavior, the levels of IL-1 $\beta$ (Fig. 2c) as well as glial markers GFAP (astrocytes; Fig. 2d) and CD11b (microglia/macrophage; Fig. 2d) were significantly increased in the dorsal horn of the spinal cord. These events were significantly attenuated by FTY720 (Fig. 2ce). This is intriguing in light of the documented role of IL-1 $\beta$ in opioid-induced dependence. Previous studies reveal that morphine-induced IL- $1 \beta$ release in the spinal cord contributes to the development of withdrawal [4547] and to a broad range of spinal adaptations that contribute to opioid physical dependence [48]. These mechanisms are varied and implicate the ability of IL- $1 \beta$ to enhance presynaptic glutamate release [49] and reduce glial glutamate uptake [50], thus leading to enhanced glutamatergic signaling within the spinal cord [48]. Additionally, IL-1 $\beta$ synergizes with other inflammatory cytokines to enhance interferon-gamma production that can downregulate the potent anti-inflammatory cytokine, interleukin-10 (IL-10) [51, 52]. This imbalance between pro- and anti-inflammatory cytokine productions has been postulated to underlie the increased neuronal excitability in the spinal cord following opioid withdrawal $[40,46]$. The mechanisms whereby naloxoneprecipitated withdrawal triggers sphingolipid alteration are not known. Previous studies have shown that opioids acting at the $\mu$-opioid receptor can cause receptor internalization and trigger oxidative stress [53] that can enhance central neuroimmune signaling and stimulate sphingolipid metabolism [54]. However, morphine and its metabolite morphine-3-glucudonide can also activate toll-like receptor 4 (TLR4) [55], a pattern recognition receptor that directly activates innate immune and inflammatory pathways. TLR4 is activated following naloxoneprecipitated withdrawal $[43,55,56]$, and its inhibition ameliorates withdrawal behaviors [57]. TLR4 activation can activate enzymes involved in ceramide and S1P metabolism such as serine palmitoyl-transferase and sphingosine kinase $[58,59]$. The role of TLR4 in opioidinduced sphingolipid metabolism dysregulation is under investigation.

Our findings in this study were limited to the effects of S1PR1 signaling had on the physical manifestation of withdrawal in rodent models. These physical symptoms parallel the somatic withdrawal symptoms in humans that include myalgia, hyperalgesia, chills, and stomach cramping [60]. However, opioid withdrawal syndrome also has negative affective aspects that include stress, malaise, emotional pain, anxiety, and depression [60, 61]. Collectively, the physical and affective components provide a negative reinforcement that can motivate opioid seeking behaviors [61]. The affective aspects of opioid withdrawal are quite complex and will require extensive studies to understand how S1PR1 signaling may impact their development. Moreover, our studies focused on the effects in male mice as they have been reported to exhibit greater physical withdrawal symptoms and sensitivity to naloxone (i.e., less naloxone to induce withdrawal) than females $[60,61]$. Future studies will need to include the effects in females to parse out any potential sexdependent difference. Despite these limitations, our current findings remain very exciting because they identify a new area of investigation with a high potential for quick development of desperately needed therapies to treat and prevent opioid withdrawal. Several S1PR1 functional and competitive antagonists have been developed over the last decade. Two S1PR1 functional antagonists are now FDA-approved for the treatment of multiple sclerosis: the pro-drug FTY720 (fingolimod; Gilenya ${ }^{\circ}$, Novartis) that was approved in 2010 [31] and ozanimod (RPC1063, Zeposia', Celgene) that was approved in 2020 [62, 63]. S1PR1 competitive antagonists such as NIBR-15 [19] and TASP0277308 [64] are in advanced preclinical development for a variety of disease states.

\section{Conclusions}

Our findings provide evidence that activation of the de novo pathway and activation of the S1P/S1PR1 axis contributes functionally to morphine-precipitated withdrawal through increased glial cell reactivity and neuroinflammation in male mice. Our findings are promising and warrant further in depth investigation in that they offer a potential strategy whereby FDA-approved S1PR1 antagonists may be used as opioid adjuncts addressing a pressing and unmet medical need.

\section{Abbreviations \\ CNS: Central nervous system; GFAP: Glial fibrillary acid protein; IL-

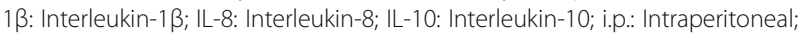 i.th: Intrathecal; LC-ESI-MS/MS: Liquid chromatography-electrospray ionization-tandem mass spectrometry; NLRP3: Nucleotide-binding domain (NOD)-like receptor protein 3; OHH: Opioid-induced hyperalgesia; \\ S1P: Sphingosine-1-phosphate; S1PR1-5: Sphingosine-1-phosphate receptors 1-5; SMase: Sphingomyelinase; SPT: Serine palmitoyl transferase; TLR4: Toll- like receptor 4; TNF: Tumor necrosis factor}

\section{Acknowledgements}

Not applicable

\section{Authors' contributions}

$\mathrm{MRH}$ and DS designed the study. MRH, KJ, ZC, SS, and VS performed experiments. WN provided reagents. TD, MRH, KB, and SS analyzed the data. TD, MRH, KB, WN, SS, and DS wrote the manuscript that was revised by all authors. All authors read and approved the final manuscript. 


\section{Funding}

This work was supported by grants from the National Institute of Drug Abuse (R21DA023056; Dr. Salvemini and RO1DA043543; Drs. Salvemini and Spiegel), Saint Louis University President's Research Fund (Dr. Salvemini), and Australian Research Fellowship (DP110100297 \& FT180100565 MRH).

\section{Availability of data and materials}

All data generated or analyzed during this study are included in this published article.

\section{Ethics approval and consent to participate}

All animal studies were performed in accordance with the International Association for the Study of Pain, the National Institutes of Health guidelines on laboratory animal welfare and approved by the Saint Louis University Institutional Animal Care and Use Committee, and the University of Adelaide Animal Ethics Committee (Ethics approval number M-60-2009).

\section{Consent for publication}

\section{Not applicable}

\section{Competing interests}

No conflict of interest.

\begin{abstract}
Author details
${ }^{1}$ Henry and Amelia Nasrallah Center for Neuroscience, Saint Louis University School of Medicine, 1402 South Grand Blvd, St. Louis, MO 63104, USA.

${ }^{2}$ Department of Pharmacology and Physiology, Saint Louis University School of Medicine, 1402 South Grand Blvd, St. Louis, MO 63104, USA. ${ }^{3}$ Discipline of Physiology, University of Adelaide, Adelaide, South Australia 5005, Australia. ${ }^{4}$ Institute for Photonics and Advanced Sensing, University of Adelaide, Adelaide, South Australia 5005, Australia. ${ }^{5}$ ARC Centre of Excellence for Nanoscale BioPhotonics, University of Adelaide, Adelaide, South Australia 5005, Australia. ${ }^{6}$ Department of Pharmaceutical Sciences, School of Pharmacy, Southern Illinois University Edwardsville, 200 University Park, Edwardsville, IL 62026, USA. ${ }^{7}$ Department of Biochemistry and Molecular Biology, Virginia Commonwealth University, School of Medicine, $1101 \mathrm{E}$ Marshall St, Richmond, VA 23298, USA.
\end{abstract}

\section{Received: 20 August 2020 Accepted: 30 September 2020}

\section{Published online: 22 October 2020}

\section{References}

1. Angst MS, Clark JD. Opioid-induced hyperalgesia: a qualitative systematic review. Anesthesiology. 2006;104:570-87.

2. Collett BJ. Opioid tolerance: the clinical perspective. Br J Anaesth. 1998;81: 58-68.

3. Volkow ND, McLellan AT. Opioid abuse in chronic pain--misconceptions and mitigation strategies. N Engl J Med. 2016;374:1253-63.

4. Doyle TM, Janes K, Chen Z, Grace PM, Esposito E, Cuzzocrea S, et al. Activation of sphingosine-1-phosphate receptor subtype 1 in the central nervous system contributes to morphine-induced hyperalgesia and antinociceptive tolerance in rodents. Pain. 2020

5. Muscoli C, Doyle T, Dagostino C, Bryant L, Chen Z, Watkins LR, et al. Counter-regulation of opioid analgesia by glial-derived bioactive sphingolipids. J Neurosci. 2010;30:15400-8.

6. Maceyka M, Spiegel S. Sphingolipid metabolites in inflammatory disease Nature. 2014;510:58-67.

7. Hannun YA, Obeid LM. Sphingolipids and their metabolism in physiology and disease. Nat Rev Mol Cell Biol. 2018;19:175-91.

8. Salvemini D, Doyle T, Kress M, Nicol G. Therapeutic targeting of the ceramide-to-sphingosine 1-phosphate pathway in pain. Trends Pharmacol Sci. 2013:34:110-8.

9. Welch SP, Sim-Selley $\amalg$, Selley DE. Sphingosine-1-phosphate receptors as emerging targets for treatment of pain. Biochem Pharmacol. 2012;84:1551-62.

10. Kunkel GT, Maceyka M, Milstien S, Spiegel S. Targeting the sphingosine-1phosphate axis in cancer, inflammation and beyond. Nat Rev Drug Discov. 2013;12:688-702.

11. Takabe K, Paugh SW, Milstien S, Spiegel S. "Inside-out" signaling of sphingosine-1-phosphate: therapeutic targets. Pharmacol Rev. 2008:60: $181-95$
12. Le Stunff H, Milstien S, Spiegel S. Generation and metabolism of bioactive sphingosine-1-phosphate. J Cell Biochem. 2004;92:882-99.

13. Healy LM, Antel JP. Sphingosine-1-phosphate receptors in the central nervous and immune systems. Curr Drug Targets. 2016;17:1841-50.

14. Tham CS, Lin FF, Rao TS, Yu N, Webb M. Microglial activation state and lysophospholipid acid receptor expression. Int J Dev Neurosci. 2003;21:431-43.

15. Choi JW, Chun J. Lysophospholipids and their receptors in the central nervous system. Biochim Biophys Acta. 1831;2013:20-32.

16. Groves A, Kihara Y, Chun J. Fingolimod: direct CNS effects of sphingosine 1phosphate (S1P) receptor modulation and implications in multiple sclerosis therapy. J Neurol Sci. 2013;328:9-18.

17. Burma NE, Kwok CH, Trang T. Therapies and mechanisms of opioid withdrawal. Pain Manag. 2017;7:455-9.

18. Dunn KE, Huhn AS, Bergeria CL, Gipson CD, Weerts EM. Non-opioid neurotransmitter systems that contribute to the opioid withdrawal syndrome: a review of preclinical and human evidence. J Pharmacol Exp Ther. 2019;371:422-52.

19. Angst D, Janser $P$, Quancard J, Buehlmayer $P$, Berst F, Oberer L, et al. An oral sphingosine 1-phosphate receptor $1(\mathrm{~S} 1 \mathrm{P}(1))$ antagonist prodrug with efficacy in vivo: discovery, synthesis, and evaluation. J Med Chem. 2012;55: 9722-34.

20. Liu L, Coller JK, Watkins LR, Somogyi AA, Hutchinson MR. Naloxoneprecipitated morphine withdrawal behavior and brain IL-1 beta expression: comparison of different mouse strains. Brain Behav Immun. 2011;25:1223-32.

21. Fdez Espejo E, Cador M, Stinus L. Ethopharmacological analysis of naloxoneprecipitated morphine withdrawal syndrome in rats: a newly-developed "etho-score". Psychopharmacology. 1995;122:122-30.

22. Hutchinson MR, Lewis SS, Coats BD, Skyba DA, Crysdale NY, Berkelhammer DL, et al. Reduction of opioid withdrawal and potentiation of acute opioid analgesia by systemic AV411 (ibudilast). Brain Behav Immun. 2009;23:240-50.

23. Gellert VF, Holtzman SG. Development and maintenance of morphine tolerance and dependence in the rat by scheduled access to morphine drinking solutions. J Pharmacol Exp Ther. 1978;205:536-46.

24. Hylden JL, Wilcox GL. Intrathecal morphine in mice: a new technique. Eur J Pharmacol. 1980:67:313-6.

25. Yosten GL, Harada CM, Haddock C, Giancotti LA, Kolar GR, Patel R, et al. GPR160 de-orphanization reveals critical roles in neuropathic pain in rodents. J Clin Invest. 2020;130:2587-92.

26. Stockstill K, Doyle TM, Yan X, Chen Z, Janes K, Little JW, et al. Dysregulation of sphingolipid metabolism contributes to bortezomib-induced neuropathic pain. J Exp Med. 2018;215:1301-13.

27. Janes K, Little JW, Li C, Bryant L, Chen C, Chen Z, et al. The development and maintenance of paclitaxel-induced neuropathic pain require activation of the sphingosine 1-phosphate receptor subtype 1. J Biol Chem. 2014;289: 21082-97.

28. Cai L, Oyeniran C, Biswas DD, Allegood J, Milstien S, Kordula T, et al. ORMDL proteins regulate ceramide levels during sterile inflammation. J Lipid Res. 2016;57:1412-22.

29. Schneider CA, Rasband WS, Eliceiri KW. NIH image to ImageJ: 25 years of image analysis. Nat Methods. 2012;9:671-5.

30. Delgado A, Casas J, Llebaria A, Abad JL, Fabrias G. Inhibitors of sphingolipid metabolism enzymes. Biochim Biophys Acta. 2006:1758:1957-77.

31. Brinkmann V, Billich A, Baumruker T, Heining P, Schmouder R, Francis G, et al. Fingolimod (FTY720): discovery and development of an oral drug to treat multiple sclerosis. Nat Rev Drug Discov. 2010;9:883-97.

32. Nishimura H, Akiyama T, Irei I, Hamazaki S, Sadahira Y. Cellular localization of sphingosine-1-phosphate receptor 1 expression in the human central nervous system. J Histochem Cytochem. 2010;58:847-56.

33. Hofford RS, Russo SJ, Kiraly DD. Neuroimmune mechanisms of psychostimulant and opioid use disorders. Eur J Neurosci. 2019;50:2562-73.

34. Linker KE, Cross SJ, Leslie FM. Glial mechanisms underlying substance use disorders. Eur J Neurosci. 2019;50:2574-89.

35. Chen ML, Cao H, Chu YX, Cheng LZ, Liang LL, Zhang YQ, et al. Role of P2X receptor-mediated IL-18/IL-18R signaling in morphine tolerance: multiple glial-neuronal dialogues in the rat spinal cord. J Pain. 2012;13:945-58.

36. Horvath RJ, DeLeo JA. Morphine enhances microglial migration through modulation of P2X4 receptor signaling. J Neurosci. 2009;29:998-1005.

37. Raghavendra V, Rutkowski MD, DeLeo JA. The role of spinal neuroimmune activation in morphine tolerance/hyperalgesia in neuropathic and shamoperated rats. J Neurosci. 2002;22:9980-9. 
38. Song P, Zhao ZQ. The involvement of glial cells in the development of morphine tolerance. Neurosci Res. 2001;39:281-6.

39. Jokinen $V$, Sidorova $Y$, Viisanen $H$, Suleymanova I, Tiilikainen $H$, Li Z, et al. Differential spinal and supraspinal activation of glia in a rat model of morphine tolerance. Neuroscience. 2018;375:10-24.

40. Grace PM, Maier SF, Watkins LR. Opioid-induced central immune signaling: implications for opioid analgesia. Headache. 2015;55:475-89.

41. Watkins LR, Hutchinson MR, Johnston IN, Maier SF. Glia: novel counterregulators of opioid analgesia. Trends Neurosci. 2005;28:661-9.

42. Raghavendra V, Tanga FY, DeLeo JA. Attenuation of morphine tolerance, withdrawal-induced hyperalgesia, and associated spinal inflammatory immune responses by propentofylline in rats. Neuropsychopharmacology. 2004;29:327-34.

43. Watkins LR, Hutchinson MR, Rice KC, Maier SF. The "toll" of opioid-induced glial activation: improving the clinical efficacy of opioids by targeting glia. Trends Pharmacol Sci. 2009;30:581-91.

44. Doyle TM, Chen Z, Durante M, Salvemini D. Activation of sphingosine-1phosphate receptor 1 in the spinal cord produces mechanohypersensitivity through the activation of inflammasome and IL-1 beta pathway. J Pain 2019;20:956-64

45. Shavit $Y$, Wolf G, Goshen I, Livshits D, Yirmiya R. Interleukin-1 antagonizes morphine analgesia and underlies morphine tolerance. Pain. 2005:115:50-9.

46. Hutchinson MR, Shavit Y, Grace PM, Rice KC, Maier SF, Watkins LR. Exploring the neuroimmunopharmacology of opioids: an integrative review of mechanisms of central immune signaling and their implications for opioid analgesia. Pharmacol Rev. 2011;63:772-810.

47. Johnston IN, Milligan ED, Wieseler-Frank J, Frank MG, Zapata V, Campisi J, et al. A role for proinflammatory cytokines and fractalkine in analgesia, tolerance, and subsequent pain facilitation induced by chronic intrathecal morphine. J Neurosci. 2004;24:7353-65.

48. Liu WT, Han Y, Liu YP, Song AA, Barnes B, Song XJ. Spinal matrix metalloproteinase-9 contributes to physical dependence on morphine in mice. J Neurosci. 2010;30:7613-23.

49. Yan X, Weng HR. Endogenous interleukin-1 beta in neuropathic rats enhances glutamate release from the primary afferents in the spinal dorsal horn through coupling with presynaptic N-methyl-D-aspartic acid receptors. J Biol Chem. 2013;288:30544-57.

50. Sama MA, Mathis DM, Furman JL, Abdul HM, Artiushin IA, Kraner SD, et al. Interleukin-1 beta-dependent signaling between astrocytes and neurons depends critically on astrocytic calcineurin/NFAT activity. J Biol Chem. 2008; 283:21953-64

51. Raices RM, Kannan Y, Sarkar A, Bellamkonda-Athmaram V, Wewers MD. A synergistic role for IL-1beta and TNFalpha in monocyte-derived IFNgamma inducing activity. Cytokine. 2008;44:234-41.

52. Donnelly RP, Freeman SL, Hayes MP. Inhibition of IL-10 expression by IFNgamma up-regulates transcription of TNF-alpha in human monocytes. J Immunol. 1995;155:1420-7

53. Koch T, Seifert A, Wu DF, Rankovic M, Kraus J, Borner C, et al. Mu-opioid receptor-stimulated synthesis of reactive oxygen species is mediated via phospholipase D2. J Neurochem. 2009;110:1288-96.

54. Won JS, Singh I. Sphingolipid signaling and redox regulation. Free Radic Biol Med. 2006;40:1875-88.

55. Wang X, Loram LC, Ramos K, de Jesus AJ, Thomas J, Cheng K, et al. Morphine activates neuroinflammation in a manner parallel to endotoxin. Proc Natl Acad Sci U S A. 2012;109:6325-30.

56. Zhang $\mathrm{H}$, Largent-Milnes TM, Vanderah TW. Glial neuroimmune signaling in opioid reward. Brain Res Bull. 2020;155:102-11.

57. Hutchinson MR, Zhang Y, Shridhar M, Evans JH, Buchanan MM, Zhao TX, et al. Evidence that opioids may have toll-like receptor 4 and MD-2 effects. Brain Behav Immun. 2010;24:83-95.

58. Sims K, Haynes CA, Kelly S, Allegood JC, Wang E, Momin A, et al. Kdo2-lipid a, a TLR4-specific agonist, induces de novo sphingolipid biosynthesis in RAW264.7 macrophages, which is essential for induction of autophagy. J Biol Chem. 2010;285:38568-79.

59. Spiegel S, Milstien S. The outs and the ins of sphingosine-1-phosphate in immunity. Nat Rev Immunol. 2011;11:403-15.

60. Pergolizzi JV Jr, Raffa RB, Rosenblatt MH. Opioid withdrawal symptoms, a consequence of chronic opioid use and opioid use disorder: current understanding and approaches to management. J Clin Pharm Ther. 2020;45: 892-903.
61. Koob GF. Neurobiology of opioid addiction: opponent process, hyperkatifeia, and negative reinforcement. Biol Psychiatry. 2020;87:44-53.

62. U.S. Food and Drug Administration approves Bristol Myers Squibb's ZEPOSIA ${ }^{\circledast}$ (ozanimod), a new oral treatment for relapsing forms of multiple sclerosis [https://www.businesswire.com/news/home/20200326005222/en/].

63. Lamb YN. Ozanimod: first approval. Drugs. 2020;80:841-8.

64. Fujii $Y$, Hirayama T, Ohtake H, Ono N, Inoue T, Sakurai T, et al. Amelioration of collagen-induced arthritis by a novel S1P1 antagonist with immunomodulatory activities. J Immunol. 2012;188:206-15.

\section{Publisher's Note}

Springer Nature remains neutral with regard to jurisdictional claims in published maps and institutional affiliations.
Ready to submit your research? Choose BMC and benefit from:

- fast, convenient online submission

- thorough peer review by experienced researchers in your field

- rapid publication on acceptance

- support for research data, including large and complex data types

- gold Open Access which fosters wider collaboration and increased citations

- maximum visibility for your research: over $100 \mathrm{M}$ website views per year

At BMC, research is always in progress.

Learn more biomedcentral.com/submissions 